\title{
Ultrasound-Assisted Extraction for Soluble Antimony(III) and Antimony(V) Speciation in Leigongteng by Hydride Generation Inductively Coupled Plasma Atomic Emission Spectrometry
}

\author{
Jinrong Feng* \\ College of Material and Chemical Engineering,Pingxiang University, Pingxiang 337000, ,China
}

\begin{abstract}
A simple and rapid ultrasound assisted extraction method with hydrochloric acid for antimony speciation in Chinese traditional medicine leigongteng was developed. Antimony(III) is selectively reduced in a citric acid buffer solution at $\mathrm{pH} 3$ in the presence of antimony $(\mathrm{V})$, where no reduction of antimony $(\mathrm{V})$ take place. Antimony $(\mathrm{V})$ is pre-reduced to antimony(III) and reduced to stibine at the same $\mathrm{pH}$, so antimony $(\mathrm{V})$ is then obtained by subtraction . A relative standard deviation of 3.9 and $4.5 \%$ and a detection limit of 0.3 and $2.4 \mu \cdot \mathrm{g} \mathrm{L}^{-1}$ for $\mathrm{Sb}(\mathrm{III})$ and total antimony has been obtained, respectively. The recovery in the range of 93 to $105 \%$.
\end{abstract}

\section{Introduction}

Antimony and its compounds are listed as priority pollutants by the US Environmental Protection Agency (EPA) and the German Research Community (DFG) underlining the increasing environmental concern about $\mathrm{Sb}[1,2]$. As with other elements, the toxicity of $\mathrm{Sb}$ and its compounds is strongly dependent on the chemical form and oxidation states.Generally, Inorganic Sb(III) is ten times more toxic than inorganic $\mathrm{Sb}(\mathrm{V})$ [3]. Therefore, its speciation analysis appears necessary[4].

Antimony species are present in various Chinese medicine samples at low concentration levels. Hence the extraction of antimony species from the sample matrix is one of the most important steps of an analytical method[5-7]. The extraction should be performed in such a way that the analyte is separated together with the minimum interference from the interfering matrix, without either loss, contamination or change in speciation. Many procedures for the extraction of antimony species in solid samples have been published and have recently been reviewed:coprecipitation[8,9], solvents extraction[10,11], ion exchang[12,13], sorption preconcentration and separation[14,15]. These sample preparation methods mentioned above suffer from disadvantages such as solvents and time consuming problems and contamination or loss errors. Supercritical fluid extraction offers an alternative sample preparation method for speciation analysis but the expensive equipment required increases the cost of the analysis[16].

The efficiency of microwave[6] or ultrasound assisted extraction $[6,17]$ method for sample extraction has been evaluated for different biological tissues. Microwaves and ultrasound facilitate and accelerate steps in the pre-treatment of solid samples such as solid-liquid extraction. These techniques can overcome the disadvantages of conventional extraction procedures in terms of time, efficiency and solvent consumption. But the absorption of microwave energy causes rapid heating of the extraction medium may led to the degradation or transformation of antimony species, so ultrasoundassisted extraction is a suitable sample pretreatment method[17,18].
The aim of this study was to develop a method that would permit the rapid separation antimony species from solid sample and determination the soluble antimony species without chromatographic separation steps. The determination of antimony(III) and antimony(V) was based on their different efficiency according to the acid medium concentration. The method was validated by the analysis of real sample.

\section{Experimental}

\subsection{Apparatus}

An inductively coupled plasma atomic emission spectrometer(Optima2000DV,USA) was used with a power of $1.3 \mathrm{KW}$ and a generator radiofrequency of 40.68MHZ.The self-made hydride generator was described in detail previously [19]. The extractions were performed with a ultrasonic washing machine (SK3200H,Shanghai,China).A PHSJ-4A pH meter was used in extract treatment(LeiCi,Shanghai,China).

\subsection{Reagents}

All reagents used were of analytical reagents grade and sub-boiled water(Zhangsu,China) was used throughout. A stock standard solution (1000mg $\cdot \mathrm{L}^{-1}$ ) of antimony(III) was prepared by dissolving $0.1197 \mathrm{~g}$ $\mathrm{Sb}_{2} \mathrm{O}_{3}$ (99.0\%,GuangZhou,China) in $10 \mathrm{ml}$ hydrochloric acid and diluting to $100 \mathrm{~mL}$. A stock standard solution $\left(1000 \mathrm{mg} \cdot \mathrm{L}^{-1}\right)$ of antimony $(\mathrm{V})$ was prepared by dissolving $0.2085 \mathrm{~K}_{4} \mathrm{Sb}_{2} \mathrm{O}_{7} \cdot 4 \mathrm{H}_{2} \mathrm{O}(99.0 \%$,Shanghai,China) in 10 $\mathrm{mL}$ hydrochloric acid and diluting to $100 \mathrm{~mL}$. Working antimony solution s were prepared daily by dilution.

$2 \%(\mathrm{~m} / \mathrm{v})$

sodium tetrahydroborate(III)(96\%,,Shanghai,China) solution was prepared in $0.1 \%(\mathrm{~m} / \mathrm{v})$ sodium hydroxide and filtered with a filter paper before use.

$5 \%(\mathrm{~m} / \mathrm{v})$ potassium iodine(99.8\%,Chengdu,China) $-5 \%(\mathrm{~m} / \mathrm{v})$ ascorbic acid(99.7\%,Guangzhou,China) was prepared in sub-boiled water. The pHs of samples were adjusted by sodium hydroxide. 


\subsection{Sample pretreatment}

$100 \mathrm{~g}$ herbal sample was homogenized with a grinder and blender, and dried at $60 \sim 65^{\circ} \mathrm{C}$ for $5 \mathrm{~h}$. The dry sample was ground to powder. A $0.5000 \mathrm{~g}$ portion of sample and $10 \mathrm{ml}$ of $2 \mathrm{~mol} \cdot \mathrm{L}^{-1}$ hydrochloric acid were placed in a taper flask and sealed with sealing band, and sonicated for 50min. After extraction, the sample solution was filtered with $0.45 \mu \mathrm{m}$ filter diaphram. The filter solution was quantitatively transferred into $25 \mathrm{~mL}$ calibrated flask and diluted to volume with $2 \mathrm{~mol} \cdot \mathrm{L}^{-1}$ hydrochloric acid. Blanks were prepared with the same reagents undergoing a similar ultrasonic treatment. All are stored at $4^{\circ} \mathrm{C}$.

\section{Results and Discussion}

\subsection{Effect of acidity of solution}

Antimony(III) and antimony(V) is highly dependent upon the acidity of solution. As shown in Figure 1, antimony(III) and antimony(V) is highly dependent upon the acidity of solution. Antimony hydride generated from antimony(III) is easily produced at $\mathrm{pH} 1.0 \sim 4.5$, the maximum difference of signal intensity of antimony(III) and antimony $(\mathrm{V})$ is produced at $\mathrm{pH} 3$ and the interference of antimony $(\mathrm{V})$ to antimony(III) is nominal. Thus antimony(III) was determined in $0.2 \mathrm{~mol} \cdot \mathrm{L}^{-1}$ citric acid solution whose $\mathrm{pH}$ was adjusted to 3 with a sodium hydroxide solution, while the total antimony was determined at the same condition after antimony $(\mathrm{V})$ was pre-reduced to antimony(III) with potassium iodineascorbic acid, gaining the concentration of antimony $(\mathrm{V})$ by difference.

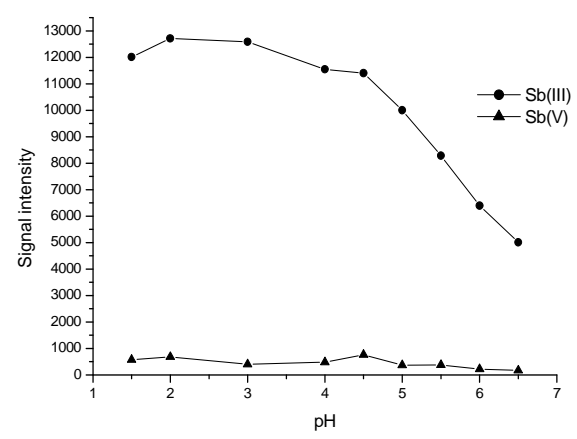

Fig.1. Effect of acidity on antimony signal intensity

\subsection{Effect of the amount of buffer solution on signal intensity}

Figure 2 shows the effect of citric acid concentration on the intensity by $50 \mathrm{ng} \cdot \mathrm{m} \mathrm{L}^{-1}$ antimony(III) at $\mathrm{pH} 3$.We can see that the intensity is the highest when the amount of buffer solution is $1 \mathrm{~mL}$. For the determination, $1 \mathrm{~mL}$ $2 \mathrm{~mol} \cdot \mathrm{L}^{-1}$ cirtic acid buffer solution was used.

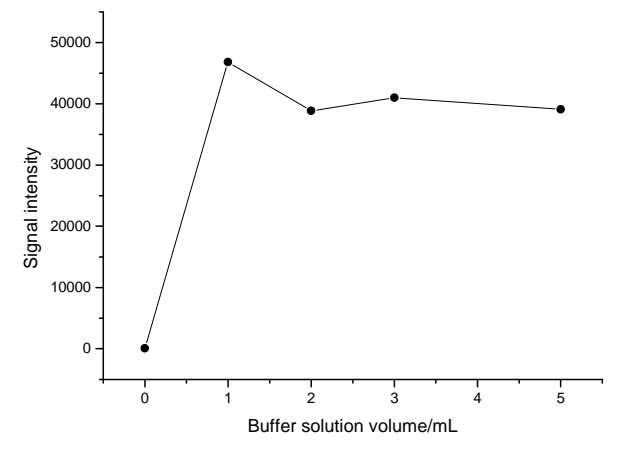

Fig.2 Effect of buffer volume on the antimony emission intensity

\subsection{Effect of sodium tetrahydroborate(III) concentration on signal intensity}

Figure 3 shows the effect of sodium tetrahydroborate(III) concentration on the intensities. The intensities increases as the sodium tetrahydroborate(III) concentration was up to $2 \%(\mathrm{~m} / \mathrm{v})$. The plasma is instable when the concentration of sodium tetrahydroborate(III) was above $2 \%(\mathrm{~m} / \mathrm{v})$. In this system, $2 \%(\mathrm{~m} / \mathrm{v})$ of sodium tetrahydroborate(III) was the optimal concentration.

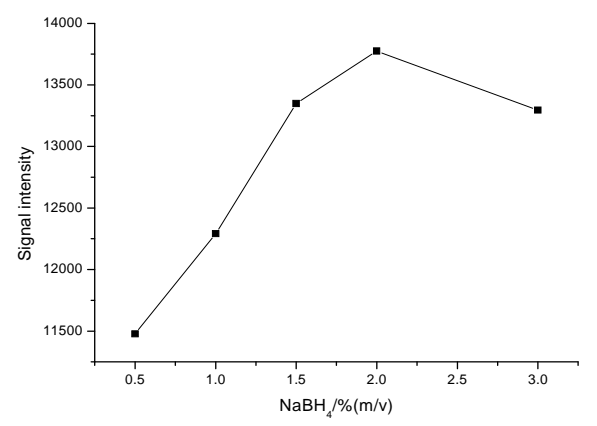

Fig.3 Effect of $\mathrm{NaBH}_{4}$ concentration on antimony signal intensity

\subsection{Effect of the amount of pre-reduce reagent on on signal intensity}

Since the intensities of antimony(V) were lower than of antimony(III) at higher acidic solution, as shown in Figure 1, so potassium iodine and ascorbic acid was added to pre-reduce antimony $(\mathrm{V})$ to antimony(III), moreover, the addition of pre-reduce reagent may reduce the interference of Copper, Cobalt, Nickel, Bismuth. Figure 4 shows the effect of the amount of potassium iodine and ascorbic acid on the intensity of antimony $(\mathrm{V})$. When $3 \mathrm{~mL}$ of the $5 \%(\mathrm{~m} / \mathrm{v})$ potassium iodine $-5 \%(\mathrm{~m} / \mathrm{v})$ ascorbic acid was added in the $2 \mathrm{~mol} \cdot \mathrm{L}^{-}$ ${ }^{1}$ hydrochloric acid medium,the same intensity as those of antimony(III) was obtained. 


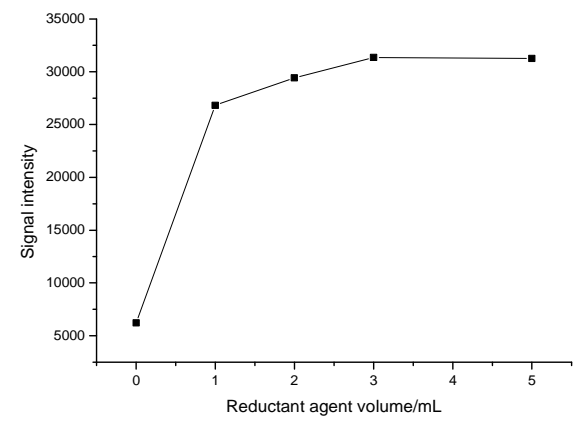

Fig.4 Effect of pre-reductant agent volume on antimony emission intensity

\subsection{Optimization of ultrasound-assisted extraction}

Several variable, such as hydrochloric acid concentration, hydrochloric acid volume, extraction time, were optimized in order to achieve quantitative extraction of antimony species.

The hydrochloric acid concentration was seen to be a critical parameter. Figure 5 shows the effect of hydrochloric acid concentration on extracting efficiency. The extracting efficiency increased and reached a maximum as the concentration of hydrochloric acid was $2 \mathrm{~mol} \cdot \mathrm{L}^{-1}$. For the extraction, $2 \mathrm{~mol} \cdot \mathrm{L}^{-1}$ hydrochloric acid was used.

Figure 6 and 7 shows the effect of hydrochloric acid volume and extraction time, respectively. The extracting efficiency is constant when the volume of hydrochloric acid in the range of 7.5 to $10 \mathrm{~mL}$. So we selected $10 \mathrm{~mL}$ $2 \mathrm{~mol} \cdot \mathrm{L}^{-1}$ hydrochloric acid as the optimized volume. The highest extracting efficiency was gained as the extraction time was 50min. When the extraction time was above 50min, the extracting efficiency otherwise reduced. In conclusion, the antimony species were extracted from herbal sample when adding $10 \mathrm{~mL} 2 \mathrm{~mol} \cdot \mathrm{L}^{-1}$ hydrochloric acid and extracting 50min.

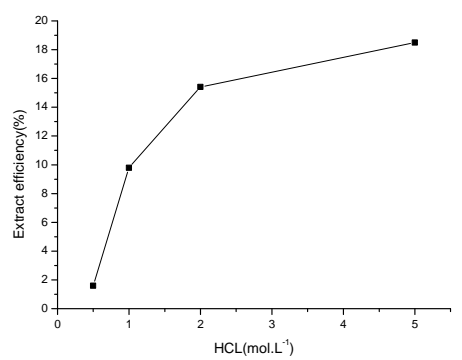

Fig.5 Effect of hydrochloric acid concentration on extracting efficiency

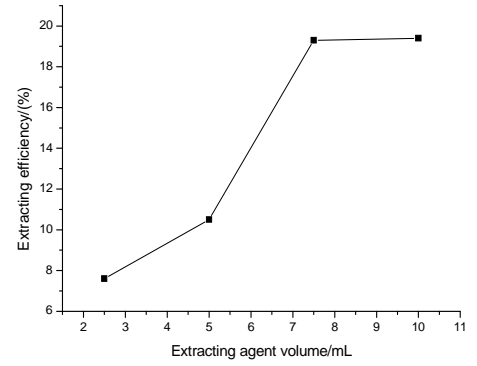

Fig.6 Effect of extracting volume on extracting efficiency

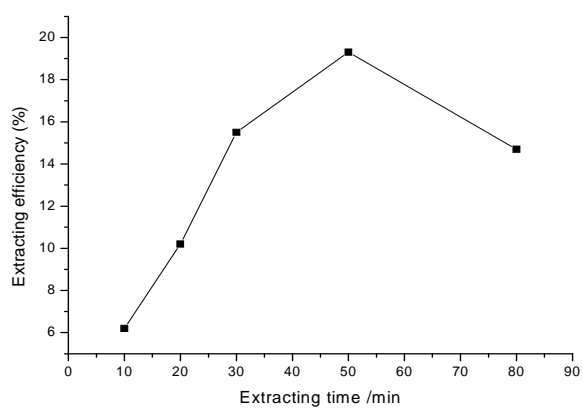

Fig 7 The effect of extracting time on extracting efficiency

\subsection{Interferences}

A number of ions, especially transition metal cations, are interferenced with borohydride reduction. Thus, the influences of common interferences on the signal of a $50 \mathrm{ng} \cdot \mathrm{mL}^{-1}$ antimony standard in the presence of potassium iodine and ascorbic acid medium was investigated. When the concentration of $\mathrm{K}(\mathrm{I}), \mathrm{Na}(\mathrm{I})$, $\mathrm{Ca}(\mathrm{II}), \mathrm{Mg}(\mathrm{II}), \mathrm{Ba}(\mathrm{II})$ were above 5000 times, the concentration of $\mathrm{Cu}(\mathrm{II}), \mathrm{Co}(\mathrm{II}), \mathrm{Ni}(\mathrm{II}), \mathrm{Al}(\mathrm{III}), \mathrm{Fe}(\mathrm{II})$, $\mathrm{Cd}(\mathrm{II}), \mathrm{Hg}(\mathrm{II})$ were above 1000 times, the concentration of $\mathrm{Ag}(\mathrm{I})$ were above 500 times, the spiked recovery of antimony was in the range of 95 to $105 \%$. The evaluation of interference demonstrated that the ions present in the majority of cases in samples influenced the measurement of antimony to an acceptable extent.

\subsection{Linearity, precision and detection limits}

Calibration curves for the determination was established from the standard solutions prepared from the working solution. The calibration curves were linear up to a concentration of in the range of 0.3 to $1000 \mathrm{ng} \cdot \mathrm{mL}^{-1}$ for antimony(III) and in the range of 2.4 to $1000 \mathrm{ng} \cdot \mathrm{mL}^{-1}$ for antimony(V). The linear relative coefficiency was 0.9999 and 0.9996, respectively. The limit of detection was set at three times the standard deviation of the blank . Under the optimized conditions, the detection $\operatorname{limits}(3 \sigma)$ of 0.3 $\mathrm{ng} \cdot \mathrm{mL}^{-1}$ for antimony(III) and $2.4 \mathrm{ng} \cdot \mathrm{mL}^{-1}$ for antimony $(\mathrm{V})$ were obtained by eleven determination of the blank. The relative standard deviations (RSDs), based on eleven determinations of $50 \mathrm{ng} \cdot \mathrm{mL}^{-1}$ standard of antimony(III) and antimony(V),were $3.9 \%$ and $4.5 \%$, respectively. 


\subsection{Sample analysis}

The proposed method was appiled to determination of antimony species in Chinese traditional herbal Leigongteng . The accuracy of the method was evaluated by recovery experiments carried out using samples spiked with known concentration of antimony.

Table 1 Results of sample analysis

\begin{tabular}{|c|c|c|c|c|c|}
\hline $\begin{array}{c}\text { Sb } \\
\text { speciation }\end{array}$ & $\begin{array}{c}\text { Measured } \\
\mu \mathrm{g} \cdot \mathrm{g}^{-1}\end{array}$ & $\begin{array}{c}\text { Add } \\
\mu \mathrm{g} \cdot \mathrm{g}^{-1}\end{array}$ & $\begin{array}{c}\text { Found } \\
\mu \mathrm{g} \cdot \mathrm{g}^{-1}\end{array}$ & $\begin{array}{c}\text { Recovery } \\
\%\end{array}$ & $\begin{array}{c}\text { RSD } \\
\%\end{array}$ \\
\hline \multirow{2}{*}{$\mathrm{Sb}(\mathrm{III})$} & \multirow{2}{*}{0.08} & 0.20 & 0.29 & 105.0 & 4.7 \\
\cline { 3 - 6 } & & 1.00 & 1.08 & 100.0 & 4.3 \\
\hline \multirow{2}{*}{$\mathrm{Sb}(\mathrm{V})$} & \multirow{2}{*}{0.39} & 2.00 & 2.26 & 93.50 & 6.5 \\
\cline { 3 - 6 } & & 3.00 & 3.37 & 99.33 & 6.3 \\
\hline
\end{tabular}

\section{Conclusion}

This work demonstrated the feasiblity for determination of soulble antimony species in Chinese traditional herbal Leigongteng by HG-ICP-AES.The antimony species can extract from herbal sample quickly over conventional extraction methods. The proposed method can help us make a further study on the chemical and biological behavior, regularity of element movement and toxicity of antimony in Chinese herbal medicine.

\section{References}

[1] Mecke, I. Lee, J.R. Baker jr., M.M. Banaszak Holl, B.G. Orr, Eur. Phys. J. E 14, 7 (2004)

[2] M. Dodd, S.A. Pergantis, W.R. Cullen, H.Li,G..K.Eigendorf and K.J.Reimer, Analyst, 121,223(1996)

[3] MAK-und BAT-werte-Liste 1996,ed, Deutsche Forschungs gemeinschaft (DFG), VCH,weiheim,1996

[4] T. D. Luckey, B. Venugopal, Plenum Press,New York, 1977.

[5] D.F.X.Donard, J.A.Caruso, Spectrochim. Acta B,1998,53:157

[6] K. Michal, E. Hendrik, Fresenius J. Anal.Chem. 368,702(2000)

[7] M.Krachlor, H.Emons,J.Zheng, Trends in Anal.Chem., 20,79(2001)

[8] F. Monteserrat, B. Nelson , Y.W. Chen, Earth Science Reviews, 57,125(2002)

[9] H. Van-der, J.T.Van-Elteren, R.N.Comand, J. Int. J. Environ. Anal. Chem., 63,67(1996)

[10] Y.C. Sun, J. Y. Yang, Anal. Chim. Acta, 395,293(1999)

[11]H.W. Sun, F.X. Qiao, R. Suo, L.X.Li,S.X. Liang, Anal. Chim. Acta, 505,255(2004)
[12]F.Edwar, P.Hugo, G..Ida De, D.G. Martine,Spectrochimica. Acta, 58,1279(2003)

[13] H. Ono, Inr. Conf.Process. Mater.Prop.,Proc.,2nd, 379 (2000)

[14]S. Garbos , M. B. Rzepecka, E. Bulska, SpectroChim. Acta, 54B,873(1999)

[15]P. Smichowski ,M.B.De-la- Ca, Y.Madrid, Spectrochim. Acta, PartB, 49B,1049(1994)

[16]S. Gaebos, E. Bulska , A. Hulanicki, Anal. Chim.Acta, 342,167(1997)

[17] C.H. Hai, Q.T. Cai, Z.X. Guo, Z.G. Yang S.B. Khoo, Analyst, 127,1380(2002)

[18] R.S. Susann, B. Carlos, J. Anal.At. Spectrom., 14,263(1999)

[19] C.M.Patricia, G. Alberto de la ,T. Carmen, M.L. Cerera,G. Migue de la , Anal.Chim. Acta, 493,195(2003)

[20] J.X Xie, B.Y. Deng, X.F.Yang , Chinese journal of Analytical Science, 20,408(2004) 